\title{
DIREITO FUNDAMENTAL À QUALIDADE DO AMBIENTE LABORAL E JUSTIÇA DO TRABALHO: UMA ABORDAGEM EMPÍRICA
}

FUNDAMENTAL RIGHT TO THE QUALITY OF THE LABOR ENVIRONMENT AND LABOR COURT: AN EMPIRICAL APPROACH

\section{DERECHO FUNDAMENTAL A LA CALIDAD DEL AMBIENTE LABORAL Y JUSTICIA DEL TRABAJO: UN ENFOQUE EMPÍRICO}

\section{Claudia Maria Petry de Faria' Haide Maria Hupffer ${ }^{2}$ Paulo José Zimermann Teixeira}

Resumo: O presente estudo examina se os magistrados da Justiça do Trabalho em suas decisões percebem o meio ambiente do trabalho no seu contexto amplo e complexo. A metodologia utilizada é a análise de conteúdo com pesquisa quantitativa e qualitativa. Foram examinados 968 pedidos de ações indenizatórias de trabalhadores do município de Novo Hamburgo/RS. Embora haja o reconhecimento da necessidade de prevenção pelo empregador, a Justiça do Trabalho ainda não se apropriou integralmente do meio 1 Doutora em Qualidade Ambiental. Universidade Feevale, Novo Hamburgo/RS, Brasil. É Docente no Curso de Graduação em Direito e Advogada. E-mail: claudia@feevale.br

2 Doutora em Direito, realizando estágio pós-doutoral na UNISINOS sob a supervisão do Prof. Dr. Wilson Engelmann. É Docente e Pesquisadora do Programa de Pós-Graduação em Qualidade Ambiental e do curso de Graduação em Direito da Universidade Feevale, Novo Hamburgo/RS, Brasil. Líder do Grupo de Pesquisa Direito e Desenvolvimento (CNPq/Feevale). E-mail: haide@feevale.br

3 Doutor em Medicina (Pneumologia) pela Universidade Federal do Rio Grande do Sul. É Médico. É Docente e Pesquisador da Universidade Federal de Ciências da Saúde de Porto Alegre e do Programa de Pós-Graduação em Qualidade Ambiental da Universidade Feevale, Novo Hamburgo/RS, Brasil. E-mail: paulojzt@feevale.br 
ambiente laboral, na medida em que diversas decisões baseiam-se apenas no laudo pericial, não havendo referência de maneira expressa aos princípios da prevenção e da precaução. Observou-se que cada parte - trabalhador - empresa - observa a si individualmente, com pouca interação do outro. O Poder Judiciário, por sua vez, também analisa individualmente, sem a percepção do todo. É um círculo vicioso: o advogado não postula e o magistrado nada fala sobre o meio ambiente do trabalho, ou seja, o sistema interno da justiça do trabalho reproduz uma visão restrita do ambiente laboral. Palavras-Chave: Meio ambiente laboral. Saúde do Trabalhador. Decisão Judicial. Risco. Justiça do Trabalho.

Abstract: This study examines whether the magistrates of the Labor Court of Novo Hamburgo, in their decisions, perceive the work environment in its broad and complex context. The methodology is a content analysis with quantitative and qualitative research. A total of 968 worker's indemnity actions claims were examined in the municipality of Novo Hamburgo/RS. Although there is recognition of the need for prevention by the employer, the Labor Court has not yet become fully appropriated, through the work environment, to the extent that many decisions are based only on expert opinion, and there is no express reference to the principles of prevention and precaution. It was observed that each part - worker - company - observes itself individually, with little interaction between them. The Judiciary, on the other hand, also analyzes individually, without the perception of the whole. It is a vicious circle: the lawyer does not postulate and the magistrate does not talk about the work environment. In other words, the internal system of labor justice reproduces a restricted view of the work environment. Keywords: Labor Environment. Worker's Health. Judicial Decision. Risk. Labor Court.

Resumen: El presente estudio examina si los magistrados de la Justicia del Trabajo en sus decisiones perciben el medio ambiente del trabajo en su contexto amplio y complejo. La metodología utilizada es el análisis de contenido con investigación cuantitativa y cualitativa. Fueron examinados 968 pedidos de acciones indemnizatorias de trabajadores del municipio de Novo Hamburgo/RS. Aunque exista el reconocimiento de la necesidad de prevención por el empleador, la Justicia del Trabajo todavía no se apropió integralmente del medio ambiente laboral, en la medida en que diversas decisiones se basan sólo en el laudo pericial, no habiendo referencia de manera expresa a los principios de la prevención y de la precaución. Se observó que cada parte - trabajador - empresa - observa a si individualmente, con poca interacción del otro. El Poder Judicial, por su vez, también analiza individualmente, sin la percepción del todo. Es un círculo vicioso: el abogado no postula y el magistrado no dice nada sobre el medio ambiente del trabajo, o sea, el 
sistema interno de la justicia del trabajo reproduce una visión restricta del ambiente laboral. Palabras-Clave: Medio ambiente laboral. Salud del Trabajador. Decisión Judicial. Riesgo. Justicia del Trabajo.

\section{INTRODUÇÃO}

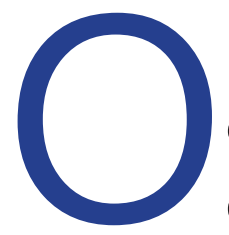
inciso I, do art. $3^{\circ}$ da Lei 6.938/81 (Política Nacional do Meio Ambiente), conceitua meio ambiente como o "conjunto de condições, leis, influências e interações de ordem física, química e biológica, que permite, abriga e rege a vida em todas as suas formas". A Constituição Federal de 1988, além de recepcionar o conceito da Política Nacional do Meio Ambiente, amplia o objeto de proteção ao tutelar não apenas o Meio Ambiente natural, mas também o cultural, o artificial, o do trabalho e o patrimônio genético. Assim, a proteção ambiental assume status de direito fundamental. É neste sentido que o presente estudo aborda a ambiência laboral como integrante do conceito jurídico de meio ambiente.

A sadia qualidade de vida, as condições existentes no ambiente laboral e a dignidade humana são pressupostos básicos para alcançar toda a complexidade inerente à ambiência laboral. O meio ambiente do trabalho é um bem de interesse público, coletivo, protegido pelos direitos difusos. Recorrer ao Poder Judiciário pode ser uma das formas de o trabalhador efetivar o direito a um ambiente laboral digno e saudável.

O meio ambiente do trabalho já foi objeto de estudos publicados em artigos científicos e em livros nacionais e internacionais. Contudo, não existe na literatura nacional pesquisa empírica com análise jurisprudencial que sistematize como a Justiça do Trabalho brasileira entende o meio ambiente do trabalho a partir das decisões prolatadas. É esta a proposta do presente estudo: evidenciar como o tema é tratado no Brasil, por meio da análise das decisões da Justiça do Trabalho de Novo Hamburgo/RS, visando identificar se a Justiça do Trabalho, ao condenar empresas por doença ocupacional, utiliza-se de fundamentação vinculada a uma análise ampla do meio ambiente do trabalho ou em aspectos pontuais e individualizados apresentados nas demandas individuais e com base em laudos 
periciais e prova testemunhal.

Quanto aos objetivos, a pesquisa tem caráter exploratório, descritivo e interpretativo. No que diz respeito à abordagem do problema, realizou-se uma análise empírica jurisprudencial, quantitativa e qualitativa. Já em relação aos procedimentos técnicos, optou-se, em razão do tema escolhido, pela pesquisa bibliográfica, documental, jurisprudencial e análise de conteúdo. Com apoio na metodologia de análise de conteúdo, proposta por Bardin e adaptada ao presente estudo, foram examinados 968 pedidos de ações indenizatórias de trabalhadores do município de Novo Hamburgo/RS do período 2005-2013 com o intuito de entender a posição dos magistrados e apresentar uma radiografia argumentativa das decisões da Justiça do Trabalho de Novo Hamburgo.

Como hipótese de trabalho, elege-se que a Justiça do Trabalho, ao condenar empresas por doença ocupacional, mais especificamente por perda auditiva e patologia pulmonar, não se utiliza de fundamentação que realmente seja vinculada a uma análise ampla do meio ambiente do trabalho, contemplando os bens jurídicos naturais e artificiais que operam e permeiam no ambiente laboral.

Para atender os objetivos e a metodologia proposta, o artigo está dividido da seguinte forma: inicialmente se apresenta o meio ambiente laboral que deve ser lido em consonância com o princípio da dignidade da pessoa humana, com os direitos e com as garantias individuais e coletivas, com os direitos sociais, bem como com o conceito de sustentabilidade, chamando a atenção para o necessário cuidado com a saúde do trabalhador. Na sequência, expõe-se que a inadequação do ambiente laboral pode representar riscos e perigos para o trabalhador com a exposição das principais doenças motivadas pelo meio ambiente do trabalho. Por fim, apresenta-se a Justiça do Trabalho como locus privilegiado para disseminar o conceito mais alargado de meio ambiente e o necessário cuidado com a qualidade do meio ambiente laboral como elemento que conforma o princípio da dignidade humana. Para tanto, apresenta-se o resultado da pesquisa empírica objetivando compreender como na prática o Sistema do Direito se posiciona frente à introdução deste componente de complexidade: o direito fundamental à qualidade do ambiente laboral. 
No presente estudo, unem-se questões relativas aos direitos que englobam a área ambiental e a trabalhista. Esses assuntos encontram ligação clara, uma vez que o meio ambiente do trabalho se encontra presente em empresas de todos os setores econômicos. As questões ambientais devem ser analisadas a fim de que o trabalhador possa desenvolver seu labor com a máxima segurança para a sua saúde.

\section{Dignidade humana e meio ambiente laboral: o necessário cuidado com a saúde do trabalhador}

A crise da degradação ambiental e as ameaças da técnica e da indústria instigam a humanidade a "tomar consciência de que o meio ambiente é constituído por elementos, coisas, espécies vegetais e animais, manipuláveis e subjugados impunemente pelo gênio humano". Igualmente, Leite e Ayala refletem que "as condições tecnológicas, industriais e formas de organização e gestões econômicas da sociedade estão em conflito com a qualidade de vida".. Ao lado dessas questões, Beck insere o conceito de Sociedade de Risco ao argumentar que os riscos ambientais têm a força destrutiva de uma guerra e são consequências indiretas de decisões tomadas no processo de modernização. Em longo prazo, os riscos do processo produtivo podem significar uma ferida profunda sobre perigos até agora impensáveis. Em Beck já não se culpa de acidentes laborais os trabalhadores que têm sua saúde arruinada, mas sim a empresa pela deficiente prevenção. ${ }^{6}$

Emerge do atual contexto uma longa lista de questões que resultam no desafio ambiental e que nada do que ocorrerá será um mero acontecimento local. A sociedade contemporânea chegou a um ponto necessário de reflexão sobre si mesma, com todos seus subsistemas: a economia, a política, a cultura e todo o conjunto de relações sociais não podem ser concebíveis como separados da natureza.

4 PENA-VEJA, Alfredo. O despertar ecológico: Edgar Morin e a ecologia complexa. Traduzido por Renato Carvalheira do Nascimento e Elimar Pinheiro do Nascimento. Rio de Janeiro: Garamond, 2010, p. 19.

5 LEITE, José Rubens Morato; AYALA, Patryck de Araújo. Dano Ambiental: do individual ao coletivo extrapatrimonial. 7. ed. rev. atual. e ampl. São Paulo: Revista dos Tribunais, 2015, p. 33.

6 BECK, Ulrich. La Sociedad del riesgo mundial: em busca de la seguridade perdida. Traducción de Rosa S. Carbó. Barcelona: Paidós Ibérica, 2008, p.50.

7 PORTO-GONÇALVES, Carlos Walter. A globalização da natureza e a natureza da globalização. 2. ed. Rio de Janeiro: Civilização Brasileira, 2006, p. 69. 
Capra, ao defender o pensamento sistêmico, argumenta que nenhum organismo individual pode viver isoladamente. A natureza ensina que os sistemas sustentáveis são possíveis, mas para isso o ser humano deve atentar para uma de suas lições mais profundas: a "sustentabilidade sempre envolve a comunidade na sua totalidade". Ser ecologicamente alfabetizado significa compreender que o meio ambiente é um sistema vivo complexo "capaz de adaptação e evolução" e que tem limites de tolerância. Se um sistema ultrapassar os limites, há o risco de todo o sistema ruir por não conseguir mais compensá-lo. ${ }^{8}$ Em O Ponto de Mutação, Capra defende que o pensamento sistêmico possibilita reconhecer que o processo evolutivo "não é determinado pelo acaso cego, mas representa um desdobramento da ordem e complexidade que pode ser visto como uma espécie de processo de aprendizagem, envolvendo autonomia e liberdade de escolha". ${ }^{9}$ Por ser interdisciplinar, o pensamento sistêmico possibilita uma mudança de paradigma ao compreender o sistema integrado e interativo de componentes biológicos e físicos. ${ }^{10} \mathrm{~A}$ crise ambiental e o meio ambiente laboral não podem ser entendidos isoladamente, uma vez que os sistemas econômico, jurídico, social e ambiental são interconectados e são interdependentes.

Conceitos complexos exigem igualmente enquadramentos complexos nas dimensões temporal e espacial, agora e no futuro, abordagens pluralistas com a participação de diversos atores. Há uma mudança de paradigma do método científico que instiga sair da produção de conhecimento do tipo descritivoanalítico para uma produção de conhecimento transformador com soluções orientadas pela transdisciplinaridade. Uma instituição capaz de reconhecer seus problemas de sustentabilidade, aprender com eles e adaptar-se para incorporálos em sua governança institucional, pode também se harmonizar num contínuo processo de despertar para outras questões que impactam a vida. ${ }^{11}$

8 CAPRA, Fritjof. Falando a Linguagem da Natureza: Princípios da Sustentabilidade. In: STONE, Michael K.; BARLOW, Zenobia. Alfabetização Ecológica: a educação das crianças para um mundo sustentável. Traduzido por Carmem Fischer. São Paulo: Cultrix, 2016, p. 48-57.

9 CAPRA, Fritjof. O Ponto de Mutação: A Ciência, a Sociedade e a Cultura Emergente. Traduzido por Álvaro Cabral. São Paulo: Cultrix, 2006, p. 281.

10 CAPRA, Fritjof. O Ponto de Mutação: A Ciência, a Sociedade e a Cultura Emergente, p. 426.

11 BAKER-SHELLEY, Alex Baker-Shelley; ZEIJL-ROZEMA, Annemarie Van; MARTENS, Pim. A conceptual synthesis of organisational transformation: How to diagnose, and navigate, pathways for sustainability at universities? Journal of Cleaner Production. v. 145, p. 262-276, March 2017. 
Em um mundo complexo, não são mais possíveis "respostas simplistas, isoladas, incapazes de religar" o fenômeno da sustentabilidade "com outros ramos dos saberes humanos". É nesse contexto que o Direito tem a difícil missão de "disseminar a sustentabilidade como princípio" para que ela seja observada em "todas as ações humanas". ${ }^{12}$ Por conseguinte, outra perspectiva importante e "interligada que envolve, de um lado, os direitos e as responsabilidades e, de outro, a sustentabilidade" é um exercício necessário que remete à reflexão sobre que planeta se quer deixar de legado e quais são as responsabilidades das gerações presentes para com as futuras gerações. ${ }^{13}$

A sustentabilidade está alicerçada nas dimensões econômicas, sociais e ambientais e obedece ao "duplo imperativo ético de solidariedade com as gerações presentes e futuras". ${ }^{14}$ E como novo paradigma de humanidade, a sustentabilidade "requer estratégias, de longo prazo, em escalas múltiplas de tempo e espaço" para buscar "mitigar o ideal de um perpétuo crescimento econômico"..15 Sustentabilidade também é vigilância e cuidado com os Direitos Fundamentais e com a vida futura de todos os organismos vivos.

A proteção do meio ambiente recebeu status de direito fundamental. A maior tarefa do direito ambiental é fazer com que as normas jurídicas possam orientar as ações, permeando todo processo de produção e reprodução da vida social, ou seja, atuar como regulador do comportamento do homem inserido em sociedade numa perspectiva adequada com a natureza. ${ }^{16}$

Há uma lógica evolutiva no conceito de meio ambiente que, ao longo das últimas décadas, assume uma concepção mais alargada, integrando o meio ambiente do trabalho como um direito de todo o trabalhador à sadia qualidade de vida.

12 AQUINO, Sérgio Ricardo Fernandes de. Instrução sustentável da UNASUL por meio da entropia e hermenêutica heterorreflexiva. Revista Eletrônica Direito e Política, Programa de Pós-Graduação Stricto Sensu em Ciência Jurídica da UNIVALI, Itajaí, v.8, n.3, 3. Quadrimestre 2013, p. 1710-1711.

13 STERN, Nicholas. O Caminho para um mundo mais sustentável. Traduzido por Ana Beatriz Rodrigues. Rio de Janeiro: Elsevier, 2010, p. 82.

14 SACHS, Ignacy. Desenvolvimento includente, sustentável, sustentado. Rio de Janeiro: Garamond, 2004, p. 36.

15 CARVALHO, Sonia Aparecida de; AQUINO, Sérgio Ricardo Fernandes de. O Modelo de Decrescimento, Crescimento e Desenvolvimento Sustentável Diante do Paradigma de Sustentabilidade. Rev. FSA, Teresina, v. 14, n. 1, art. 4, jan./fev. 2017, p. 97.

16 DERANI, Cristiane. Direito ambiental econômico. 3. ed. São Paulo: Saraiva, 2008, p. 62-65. 
Quando a saúde do trabalhador no seu ambiente de trabalho está em jogo, reveste-se de importância a fundamentalidade do direito ao ambiente sadio e ecologicamente equilibrado previsto no art. 225 da Constituição Federal de 1988. Ao se articular de forma difusa, o Direito Ambiental assume a garantia de uma espécie de usufruto coletivo, sustentando-se numa espécie de moral coletiva. A dignidade do trabalhador no ambiente de trabalho possui um âmbito de proteção compartilhada com o direito fundamental ao meio ambiente.

Fensterseifer fala em "uma nova dimensão ecológica para a dignidade humana" em que a qualidade ambiental pode ser considerada como um novo elemento integrante do conteúdo do princípio da dignidade humana esculpido no inciso III do art. $1^{\circ}$ da Constituição Brasileira de 1988. Portanto, assume-se neste estudo com Fensterseifer que "o conteúdo conceitual e normativo do princípio da dignidade humana está intrinsecamente relacionado à qualidade do ambiente (onde o ser humano vive, mora, trabalha, estudo, etc.)". ${ }^{17}$

Como bem pontua Aquino, a expressão Dignidade, "enquanto atributo axiológico, não se encerra como conceito pronto e definitivo". A humanidade laborou muito para internalizá-la nos Direitos Humanos Fundamentais, tanto no plano internacional como no nacional e, certamente, o caminho ainda é longo para ampliar e assegurar as "conquistas indispensáveis à manutenção do viver e conviver". Dignidade também é a "expressão de justiça, de reconhecimento ao fato que as pessoas não vivem em condições apropriadas para se ter uma vida sadia". Desta forma - e pelas razões expostas -, falar em dignidade no ambiente laboral é também reconhecer - como bem faz Aquino - que dignidade significa prover "a responsabilidade necessária quanto ao cuidado da vida" e à "preservação de todas as vidas". ${ }^{18}$ E este deve ser o eixo principal que oferece sentido ao trabalho.

O meio ambiente de trabalho envolve fatores climáticos, físicos, químicos, entre outros que permeiam a atmosfera laboral, influindo diretamente na saúde e no

17 FENSTERSEIFER, Tiago. Direitos Fundamentais e proteção do ambiente: a dimensão ecológica da dignidade humana no marco jurídico-constitucional do Estado Socioambiental de Direito. Porto Alegre: Livraria do Advogado, 2008, p. 35- 61.

18 AQUINO, Sérgio Ricardo Fernandes de. Bauman e a crítica sobre a perda da dignidade da pessoa humana em tempos líquidos. Revista Húmus. v. 6, n. 18, p. 70-88, 2016, p. 71, 72 e 86. 
bem-estar do trabalhador. A regulamentação do meio ambiente do trabalho está amparada na Constituição Federal de 1988 pela conjugação dos artigos 5०, $\$ 2^{\circ}, 7^{\circ}$ (incisos XXII E XXVI), 200, VIII e 225..$^{19}$ É direito dos trabalhadores urbanos e rurais a redução dos riscos próprios ao exercício do trabalho por meio da normatização referente à saúde, à higiene e à segurança. Ademais, o inciso VII do art. 200 da Constituição Federal inclui o meio ambiente do trabalho na proteção ambiental. Além da previsão constitucional, para a proteção do empregado em seu meio ambiente de trabalho, há uma vasta legislação infraconstitucional.

Operam-se frente a esse direito-dever as seguintes situações: o dever do empregador de fornecer um ambiente de trabalho adequado, sem riscos à saúde física e mental, fornecendo o equipamento de proteção individual e/ou coletiva apropriado ao exercício das atividades contratadas, com o direito de exigir do trabalhador o uso dos referidos equipamentos, sob pena de despedida por justa causa. Em contrapartida, emerge o direito do trabalhador de exigir do empregador o ambiente próprio e seguro para a realização das tarefas, com o dever de fazer uso do material necessário à sua segurança. A ruptura desse direito, por conta do empregador, origina, ao empregado, inclusive, a possibilidade de encerramento do contrato de trabalho por justo motivo, conforme previsão no artigo n. 483 da Consolidação das Leis do Trabalho.

O cuidado com a saúde do trabalhador ultrapassa, portanto, a condição individual, ganhando aspecto coletivo, exigindo atenção ao meio ambiente do trabalho, que é o reflexo da integração entre o homem-trabalhador em seu espaço laboral. 0 "habitat laboral" é considerado como um conjunto de bens móveis e imóveis e as condições para a prestação daquela atividade, seja remunerada, seja voluntária.

Quando o meio ambiente laboral se apresentar prejudicial, causando danos à saúde do trabalhador, poderá o Estado agir, seja por meio do Ministério do Trabalho e Emprego, seja por meio do Poder Judiciário, inclusive, por meio da Ação Civil Pública, independentemente da prestação jurisdicional individual.

Dentre outros aspectos a considerar, atender ao padrão de dignidade é também

19 GARCIA, Gustavo Filipe Barbosa. Meio Ambiente do Trabalho no contexto dos Direitos Humanos fundamentais e responsabilidade civil do empregador. Doutrinas Essenciais de Direito do Trabalho e da Seguridade Social. v. 3, p. 543-562, set. 2012, p. 544. 
atender ao padrão de salubridade no ambiente laboral. Da mesma forma - e pelas mesmas razões -, Sarlet e Fensterseifer sustentam que a proteção à dignidade humana reclama o engajamento do Estado no sentido de que o ser humano não pode ser reduzido "à condição de mero objeto das relações sociais e econômicas". A dignidade da pessoa humana, na percepção dos autores, "somente estará assegurada - em termos de condições básicas a serem garantidas pelo Estado e pela sociedade - onde a todos e a qualquer um estiver assegurada nem mais nem menos do que uma vida saudável". ${ }^{20}$ Trabalhar em ambiente laboral com qualidade ambiental é um direito fundamental do trabalhador. Já a adoção de medidas precaucionais e preventivas é dever do empreendedor.

\section{Reflexos da inadequação do meio ambiente laboral na saúde do trabalhador: principais doenças associadas}

A inadequação do ambiente laboral representa riscos à saúde do trabalhador, ocasionando não apenas os acidentes típicos, como também originando doenças ocupacionais. ${ }^{21} \mathrm{O}$ crescimento econômico não pode se apoiar "em esforços excessivos e extenuantes de seus produtores, em empregos mal pagos e em condições insalubres". O objetivo supremo da sustentabilidade é o "emprego decente". ${ }^{22}$

Sachs chama a atenção que a comunidade mundial poderia fazer uma diferença profunda para o bem-estar dos mais pobres se investisse seriamente no controle de doenças e melhorias da saúde. Tecnologias e base de conhecimento existem e investimentos em saúde se pagam. O que falta é vontade política e destinação de recursos financeiros para a prevenção. Como exemplo, Sachs cita que o controle de doenças melhora a produtividade da força de trabalho, acelera o crescimento econômico e promove a estabilidade política e social. Particularmente os mais pobres são os afetados. Todos os anos milhares de pessoas morrem de forma trágica, mortes desnecessárias e socialmente onerosas. ${ }^{23}$

$\overline{20}$ SARLET, Ingo Wolfgang. Estado Socioambiental e mínimo existencial (ecológico?): algumas aproximações. In: SARLET, Ingo Wolfgang. Estado Socioambiental e Direitos Fundamentais. Porto Alegre: Livraria do Advogado, 2010, p. 28-30.

21 MELO, Simão Raimundo. Direitos Ambiental do Trabalho e Saúde do Trabalhador. 5. ed. São Paulo: 2013, p. 83-85.

22 SACHS, Ignacy. Desenvolvimento includente, sustentável, sustentado. Rio de Janeiro: Garamond, 2004, p. 18-35.

23 SACHS, Jeffrey. An economist's view of health Bulletin of the World Health Organization. v. 80, n.2, p.167- 
Ao considerar-se o ambiente laboral, é necessário refletir que muitas das mortes trágicas indicadas por Sachs são vítimas de acidentes de trabalho, que poderiam ter sido evitadas, com a criação de um ambiente laboral saudável e adoção de medidas de segurança, proteção e prevenção.

O acidente de trabalho poderá ser dividido em acidente típico (ou acidente tipo), acidente de trajeto (ou acidente in itinere) e doença profissional. As doenças profissionais são aquelas "produzidas ou desencadeadas pelo exercício do trabalho peculiar a determinada atividade" e doenças do trabalho são aquelas "adquiridas ou desencadeadas em função das condições especiais em que o trabalho é realizado".24

As doenças de trabalho encontradasnas perícias do trabalho com mais frequência são: artrite reumatoide, osteoartrose-espondiloartrose, dor lombar na coluna vertebral, hérnia de disco, espondilise, espondilolistese, espondiloptose, cervicobraquialgia, colunopatia, meniscopatias, condromalácia patelar, fasceíte plantar, síndrome do impacto, bursite, epicondilite, tendinite, síndrome do túnel do carpo, cisto sinovial, asma brônquica, doença broncopulmonar obstrutiva crônica, antracose, silicose, pneumotórax, câncer de pele, onimicose, hipertensão arterial e estresse, disfonia e afonia, síndrome de Burnout, perda auditiva e toxoplasmose. ${ }^{25}$

Expor o trabalhador a fatores de risco configura violação do Direito à saúde, à sadia qualidade de vida e ao princípio da dignidade. A degradação do ambiente laboral trará reflexos para o indivíduo no primeiro instante, mas também para a sociedade, a quem restarão o encargo da reabilitação e os demais ônus financeiros.

No presente estudo serão examinadas as doenças ocupacionais de perda auditiva e patologia pulmonar, ambas motivadas pelo ambiente laboral. A perda auditiva induzida pelo ruído é uma doença que avança ao longo dos anos. O ruído, associado ao ambiente de trabalho, é considerado dano quando há uma exposição superior a $85 \mathrm{~dB}$ (decibéis), durante oito horas por dia, de maneira regular, ao longo de vários anos. De acordo com área afetada no sistema auditivo, a perda auditiva está dividida em três categorias, sendo elas, respectivamente, perda

169, 2002.

24 MACIEL, Fernando. Ações Regressivas Acidentárias. 2. ed. São Paulo: Ltr, 2013, p. 21.

25 PIANTÁ, José Antonio de Barros. Perícias do trabalho. Porto Alegre: Next, 2011, p.2021. 
auditiva condutiva, perda auditiva neurossensorial e perda auditiva mista. ${ }^{26}$

A perda auditiva condutiva ocorre quando o som não é conduzido de maneira eficaz pelo ouvido externo até o tímpano, assim como aos ossículos. Esse tipo de dano à audição frequentemente diminui a habilidade de ouvir sons fracos. A perda auditiva neurossensorial ocorre quando há danos ao ouvido interno, ou às vias nervosas que carregam as informações do ouvido ao cérebro. ${ }^{27} \mathrm{Na}$ maior parte dos casos, a perda auditiva neurossensorial não pode ser corrigida por via cirúrgica ou tratada de qualquer outra maneira medicinal. Já a perda auditiva mista ocorre quando há uma combinação entre a perda auditiva condutiva e a perda auditiva neurossensorial. O dano é, portanto, no tímpano e na parte interna do ouvido, ou nas suas vias nervosas.

As doenças relacionadas ao meio ambiente de trabalho ocorrem de forma silenciosa e lenta. Outro órgão humano diretamente sujeito à ação nociva dos agentes dispersos na atmosfera é o pulmão. No que se refere às doenças pulmonares, pode-se ter considerável lapso de tempo para o aparecimento dos efeitos na saúde física do indivíduo. ${ }^{28}$ À luz de tal perspectiva, Bosselmann argumenta que "sempre que ocorrer um dano ambiental, o gozo dos direitos humanos está potencialmente em perigo". Como situação padrão em muitas empresas, cita a exposição à poluição do ar ou as substâncias químicas poluentes. Neste caso, o argumento básico do autor é que o "meio ambiente não deve se deteriorar a tal ponto que o direito à vida, o direito à saúde e ao bem-estar [...] fiquem gravemente comprometidos". ${ }^{29}$

Promover o desenvolvimento humano e seu bem-estar, protegendo também os sistemas de suporte à vida da Terra é, na compreensão de Kates, objetivos do desenvolvimento sustentável. Se um sistema for afetado, este também afetará o outro. Entendido nesta perspectiva, a ciência da sustentabilidade deve ser orientada para compreender de forma integrada e estreitamente acoplada os

26 AMERICAN SPEECH-LANGUAGE-HEARING ASSOCIATION (ASHA). Conductive hearing loss. Rockville, MD 20850, USA, 2014.

27 AMERICAN SPEECH-LANGUAGE-HEARING ASSOCIATION (ASHA). 2014.

28 BRASIL. Ministério da Saúde. Cadernos de Atenção Básica, n. 5. Brasília: Ministério da Saúde, 2002, p. 22.

29 BOSSELMANN, Klaus. Direitos Humanos, Meio Ambiente e Sustentabilidade. In: SARLET, Ingo Wolfgang. Estado Socioambiental e Direitos Fundamentais. Porto Alegre: Livraria do Advogado, 2010, p. 77. 
sistemas humano-ambiente. Aplicar as contribuições de Kates ao presente estudo é indicar que o ambiente do trabalho seja um laboratório de pesquisas inter/ multi/transdisciplinares entre cientistas, profissionais das mais diversas áreas e colaboradores para minimizar os fatores de risco. Transcender suas origens disciplinares favorece o comprometimento coletivo com soluções e decisões, bem como passa a exigir uma compreensão integrativa. Nesse compromisso, refletem-se os valores de duas solidariedades: a solidariedade humana e a sensibilidade ecológica. ${ }^{30}$

O dizer de Kates pode ser empregado para estudar o meio ambiente laboral como um campo de pesquisa para médicos, engenheiros, juristas, economistas, ecologistas, biólogos, entre outros, para minimizar problemas do meio ambiente laboral. Para o caso das pneumopatias ocupacionais, que são doenças originadas pela exposição direta às substâncias presentes nos ambientes de trabalho ou provenientes do material de trabalho, a pesquisa inter/multi/transdisciplinar pode contribuir para estudar os principais agentes causadores destas doenças pulmonares. Entre os agentes já estudados, destacam-se os agentes químicos que são "substâncias químicas tóxicas, presentes nos ambientes de trabalho nas formas de gases, fumo, névoa, neblina e/ou poeira". ${ }^{31}$

As doenças respiratórias ocupacionais mais frequentes são a asma ocupacional, a doença pulmonar obstrutiva crônica (DPOC), a pneumoconiose, a rinite ocupacional e o câncer de pulmão. Como exemplo, a asma ocupacional apresenta sintomas como falta de ar, tosse, aperto e chiado no peito, bem como tosse noturna. ${ }^{32}$

A partir destas observações, concorda-se com Bosselmann que as condições ambientais sadias devem ser consideradas "como parte do direito à vida. Na medida em que esse direito protege contra riscos graves à saúde humana". ${ }^{33}$ Portanto, há uma ligação óbvia entre qualidade do ambiente laboral e saúde do trabalhador.

A manutenção de condições ambientais prejudiciais ao organismo, provocando, por consequência, as doenças apontadas, repercute em prejuízo de todos,

30 KATES, Robert W. Readings in Sustainability Science and Technology. CID Working Paper n. 213. Center for International Development, Harvard University. Cambridge, MA: Harvard University, December, 2010, p. 16-19.

31 BRASIL. Cadernos de Atenção Básica, p. 21.

32 BRASIL. Cadernos de Atenção Básica, p. 22.

33 BOSSELMANN, Klaus. Direitos Humanos, Meio Ambiente e Sustentabilidade, p. 78. 
trabalhadores, empregadores, sociedade e Estado. Trata-se, pois, de direito fundamental dos cidadãos, trabalhadores e sociedade em geral.

Os danos e os riscos ambientais no ambiente laboral são silenciosos e se espalham para outras áreas da empresa, regiões e ecossistemas. Neste sentido, registra-se do dizer de Bosselmann em outro contexto que a "'tragédia dos comuns' é que a maioria das formas de degradação ambiental são perfeitamente legais" ${ }^{34}$ Ou seja, a empresa recebeu licença ambiental para operar, mas essa licença concedida não contempla o meio ambiente laboral e não reconhece a crescente ideia de que a degradação do ambiente laboral pode resultar em graves riscos à saúde do trabalhador.

Há, portanto, um elo fundamental que deve ser observado entre um ambiente de trabalho que não atende aos dispositivos constitucionais ambientais e direitos sociais e a doença ocupacional. Assim, a expressão meio ambiente da norma constitucional deve ser lida em consonância com o princípio da dignidade da pessoa humana, os direitos e as garantias individuais e coletivos, bem como com os direitos sociais.

As doenças ocupacionais devem ser enfrentadas pelo Direito que, por seu turno, deverá comunicar-se com os demais subsistemas econômico e social, de modo a modificar as situações de risco que favorecem o aparecimento das doenças no meio ambiente laboral. O Poder Judiciário, ao ser demandado pelo trabalhador, não deve analisar somente a situação trazida no processo, mas tem o dever de estender-se sobre a condição do ambiente laboral. A repetição de acidentes de trabalho em uma mesma empresa justifica um exame mais acurado acerca do meio ambiente em que aquele trabalhador está inserido.

A partir de tal premissa, na sequência, será apresentado um estudo de caso a partir das decisões da Justiça do Trabalho de Novo Hamburgo. A realização da pesquisa empírica possibilita compreender como na prática o Sistema do Direito se posiciona frente à introdução deste componente de complexidade: o direito fundamental à qualidade do ambiente laboral. Busca-se, amparado em Pena-Veja, "chegarmos ao nó górdio do paradigma ecológico" e, de certa maneira, afastar o paradigma da simplificação ${ }^{35}$ nas decisões da Justiça do Trabalho e nas petições

34 BOSSELMANN, Klaus. Direitos Humanos, Meio Ambiente e Sustentabilidade, p.84.

35 PENA-VEJA, Alfredo. O despertar ecológico: Edgar Morin e a ecologia complexa, p. 93. 
dos advogados que, durante muito tempo, não contemplaram a qualidade do ambiente laboral como um elemento do princípio da dignidade humana.

\section{A qualidade do meio ambiente laboral sob a ótica da doença ocupacional: um estudo de caso sobre decisões da Justiça do Trabalho de Novo Hamburgo}

A Justiça do Trabalho, na sua forma atual, é integrante do Poder Judiciário Federal, tendo sua competência disciplinada pela Constituição Federal no artigo 114. Sua missão é a realização pela Justiça nas relações individuais e coletivas de trabalho. Ela está dividida em 27 Tribunais Regionais do Trabalho pelo Brasil. Os Tribunais Regionais do Trabalho têm sede nas capitais dos Estados, enquanto o órgão máximo, o Tribunal Superior do Trabalho, tem sede em Brasília.

O Tribunal Regional do Trabalho do Rio Grande do Sul é o da Quarta Região, compondo a Segunda Instância Trabalhista. No Município de Novo Hamburgo estão instaladas cinco Varas Trabalhistas que abrangem os municípios de Novo Hamburgo, Lindolfo Collor, Morro Reuter, Picada Café e Presidente Lucena.

O estudo foi realizado com base nos dados fornecidos pela Justiça do Trabalho de Novo Hamburgo no período de 2005 a 2013. A justificativa pelo lapso temporal decorre do fato de que, a partir de 08 de dezembro de 2004, com a Emenda Constitucional $n^{\circ} 45$, a competência para o exame dos acidentes de trabalho e das doenças ocupacionais passou a ser exclusivamente da Justiça do Trabalho. Anteriormente à entrada em vigor da referida Emenda, os acidentes de trabalho eram objeto de análise e julgamento pela Justiça Estadual.

A metodologia de análise de conteúdo proposta por Bardin foi adaptada para o presente estudo e organiza-se em torno dos três polos cronológicos: (I) a préanálise; (II) a exploração do material; e, por fim, (III) o tratamento dos resultados: a inferência e a interpretação. ${ }^{36}$

Na fase da pré-análise, a escolha inicial recaiu sobre as ações prolatadas na Justiça do Trabalho de Novo Hamburgo no período de 2005 a 2013, as quais continham como pedido principal as expressões "acidente de trabalho", "dano

36 BARDIN, Laurence. Análise de Conteúdo. Tradução de Luís Antero Reto e Augusto Pinheiro. São Paulo: Edições 70, 2011, p. 125. 
material" e "dano moral". Foram encontrados 1.237 processos que poderiam indicar acidentes de trabalho no sentido amplo. No refinamento da pesquisa, constatou-se que 120 (cento e vinte) processos não tratavam de acidente de trabalho e sim de postulações referente a assédio moral e, portanto, não seria objeto do presente estudo, embora também refletissem o ambiente de trabalho. Realizado novo refinamento, eliminando-se os processos que foram arquivados por ausência das partes, ou extintos sem julgamento do mérito, chegou-se ao número de 968 processos que versam sobre acidente de trabalho com pedidos de indenização por dano moral, por dano material e pensionamento vitalício.

Definido o corpus (968 processos), iniciou-se a leitura dos processos, em especial do laudo pericial e das sentenças. Na sequência, as ações foram classificadas nas seguintes categorias e temas: 1 ) Acidente de Trabalho - foram agrupados os processos que envolviam os acidentes de trabalho típicos (ou tipos, como também são denominados pela doutrina), os acidentes "initinere" (também denominados acidentes de trajetos) e as doenças ocupacionais, tendo em vista que representam o norte para as demais classificações. 2) Atividade - nesta categoria foram definidos os setores a serem estudados, a saber: indústria, comércio e serviços. 3) Resultado - nesta categoria a análise refere-se ao encerramento do mérito discutido, qual seja: sentença procedente, sentença improcedente e acordo. 4) Indenização - como reflexo das decisões, criou-se uma categoria para observar se havia condenações a título de dano material e a título de dano moral, observando também os valores. 5) Benefícios - também como consequência das decisões, criou-se uma categoria específica para verificação dos benefícios decorrentes do reconhecimento dos acidentes, quais sejam: pensionamento vitalício e aposentadoria.

Os dados foram armazenados em um banco de dados para possibilitar a análise qualitativa e quantitativa, contendo as seguintes informações: a) número do processo; b) ano de distribuição do processo; c) Vara do Trabalho; d) decisão; e) laudo pericial; f) valor de indenização por dano material; g) valor de indenização por dano moral; h) outros benefícios; i) setor; j) acidente de trabalho típico, de trajeto ou doença; h) tipo de doença; i) tipo de acidente típico.

A organização da codificação exigiu duas escolhas: o recorte e a escolha das 
categorias (classificação e agregação). Após a análise quantitativa das 968 ações, o próximo passo requeria a redução do universo da pesquisa para atender aos objetivos propostos. Assim, foi realizado um novo refinamento na pesquisa para observar demandas sobre doenças ocupacionais por entender que as mesmas são indicativas de qualidade do ambiente laboral em sentido lato. Dentre as doenças ocupacionais que integram o novo refinamento da pesquisa - LER, Perda Auditiva, Depressão, Hérnia, Síndrome do Manguito rotador, Síndrome do Túnel Do Carpo, Epicondilite e Patologia Pulmonar -, a opção foi examinar a perda auditiva e a doença pulmonar.

A Tabela 1 - mostra o total de acidentes de trabalho ocorridos no município de Novo Hamburgo no período 2005-2013 por tipo de acidente, número de acidentes com o registro da CAT (Comunicação de Acidente de Trabalho) pelas empresas, número de acidentes informados sem o registro da CAT e número de óbitos.

A Tabela 1 evidencia que, em Novo Hamburgo, no ano de 2005, foi registrado o número de 87 trabalhadores com doenças ocupacionais e, a partir de então, iniciou-se uma linha decrescente, sendo que no ano de 2012, o número caiu para apenas 11 trabalhadores com doença ocupacional informada por meio da CAT. No ano de 2013, houve significativo acréscimo no indicador mencionado, tendo havido 32 trabalhadores com doença ocupacional, indicados por meio da CAT, representando um aumento $290 \%$ em relação ao ano anterior. $\mathrm{Na}$ Tabela 1 o que também chama a atenção é o elevado número de registros de acidentes de trabalho sem o devido registro da CAT pela empresa. Verifica-se, em comparativo com a Tabela 1, que o grande número de acidentes de trabalho em sentido lato não repercute diretamente e na mesma proporção junto à Justiça do Trabalho (Tabela 2), ou seja, o número de ações ajuizadas postulando indenização é bastante reduzido. Por meio da observação dos dados pertinentes à Tabela 2, verifica-se que, embora o número de acidentes possa ser considerado alto, o número de ações ajuizadas no período de 2005-2013 (9681 acidentes) corresponde tão somente a 10\% (968). Os pedidos referem-se à indenização por dano moral, por dano material e pensionamento vitalício. 


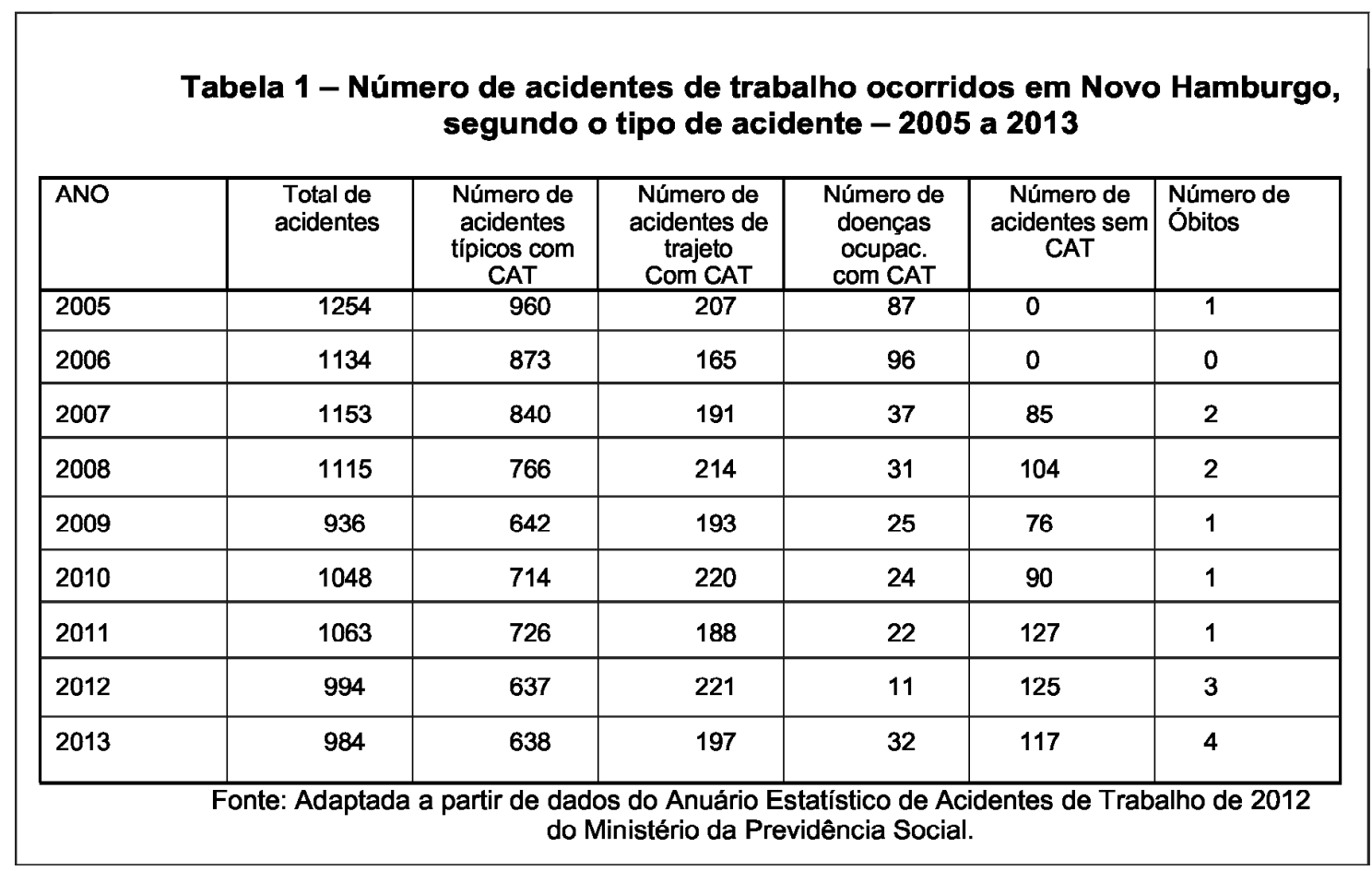

Na Tabela 2 - consta-se que o setor industrial, o qual comporta os segmentos da indústria de couros, plásticos, construção civil e metal mecânico, apresenta o maior número de demandas judiciais sobre acidente de trabalho, representando 694 processos trabalhistas impetrados na Justiça do Trabalho de Novo Hamburgo. Neste resultado também estão incluídas as doenças ocupacionais. Por sua vez, o setor do comércio alcança, no mesmo período, o número de 174 (centos e setenta e quatro) processos, enquanto o setor de serviços está representado pelo número de 100 processos. Nota-se, portanto, que o percentual de acidentes de trabalho objeto de demanda trabalhista no setor industrial corresponde a um

\begin{tabular}{|l} 
Tabela 2 - Número de Ações Ajuizadas sobre Acidente de Trabalho na \\
Justiça do Trabalho de Novo Hamburgo - 2005-2013 \\
\begin{tabular}{|l|r|r|r|r|r|r|r|r|r|r|}
\hline \multicolumn{1}{|c|}{} \\
SETORES & 2005 & 2006 & 2007 & 2008 & 2009 & 2010 & 2011 & 2012 & 2013 & TOTAL \\
\hline COMÉRCIO & 8 & 15 & 5 & 10 & 5 & 4 & 9 & 31 & 87 & 174 \\
\hline SERVIÇOS & 8 & 12 & 5 & 12 & 13 & 10 & 9 & 11 & 20 & 100 \\
\hline INDÚSTRIA & 81 & 107 & 63 & 90 & 90 & 60 & 62 & 65 & 76 & 694 \\
\hline TOTAL & 97 & 134 & 73 & 112 & 108 & 74 & 80 & 107 & 183 & 968 \\
\hline
\end{tabular} \\
\hline
\end{tabular}


percentual de 71,69\% do total no período 2005-2013, razão pela qual a opção foi analisar apenas o setor industrial em relação às doenças ocupacionais de perda auditiva e patologia pulmonar.

Em relação aos processos examinados, a pesquisa mostrou que quarenta e nove por cento (49\%) já foi julgado procedente (favorável à pretensão do trabalhador), não havendo mais possibilidade de recursos. Trinta e oito por cento (38\%) encontra-se em andamento, seja na Primeira Instância, seja em grau de recurso; e treze por cento (13\%) foi julgado improcedente, ou seja, não houve atendimento à pretensão dos trabalhadores. Na análise realizada, verificou-se que $80 \%$ dos processos julgados improcedentes o foram com base na inexistência de nexo causal entre acidente/doença e o trabalho, conforme perícia médica realizada.

Desmembrando o setor industrial, como pode ser verificado na Tabela 3, há maior incidência de processos tendo como polo passivo, ou seja, empresas reclamadas no setor coureiro-calçadista-plástico, atingindo um percentual de 58,64\% (cinquenta e oito vírgula sessenta e quatro por cento) do total de processos no setor de indústrias. O setor metalúrgico contribuiu no decorrer do período com o percentual de 12,24\% (doze vírgula vinte e quatro por cento) dos processos listados. O setor da construção civil e do mobiliário contribuiu com 7,06\% (sete vírgula zero seis por cento); enquanto o setor da indústria da alimentação, bebidas e fumo, contribuiu com 3,89\% (três vírgula oitenta e nove por cento).

A indústria química, farmacêutica e de perfumaria contribuiu com 1,87\% (um vírgula oitenta e sete por cento) e a indústria da fiação, tecelagem e do vestuário contribui com $0,86 \%$ (zero, oitenta e seis por cento) dos processos envolvendo acidentes de trabalho. Por sua vez, a indústria de papel, a de cortiça, a gráfica e de editoração contribuem com um percentual de 0,72\% (zero, setenta e dois por cento), enquanto que o restante, ou seja, 14,40\% (catorze vírgula quarenta por cento) dos processos coube a empresas não enquadradas nos demais setores pela Justiça do Trabalho.

No setor industrial, o maior número de acidentes ocorre na indústria de couro, plástico, borracha e metalúrgica, sendo plausível a constatação de que o maior número de acidentes decorra do maior número de empregados. Por meio de dados obtidos junto ao Ministério do Trabalho, observou-se que a indústria de 
couro, plástico e borracha, agregada à indústria de calçados no ano de 2013, admitiu 7.818 trabalhadores, em contraposição à indústria do papel, papelão e cortiça, que admitiu 1.029 trabalhadores e a indústria da construção civil, cujas admissões foram em número de 3.279 empregados. ${ }^{37}$ Complementando as informações acerca do número de trabalhadores, constata-se que, no ano de 2013, o setor industrial de Novo Hamburgo, composto por 3.998 indústrias, teve quadro funcional de 29.586 trabalhadores, cerca de onze mil a mais do que o setor de comércio (18.590). A construção civil, entretanto, teve um pequeno decréscimo de 24 empregados. ${ }^{38}$

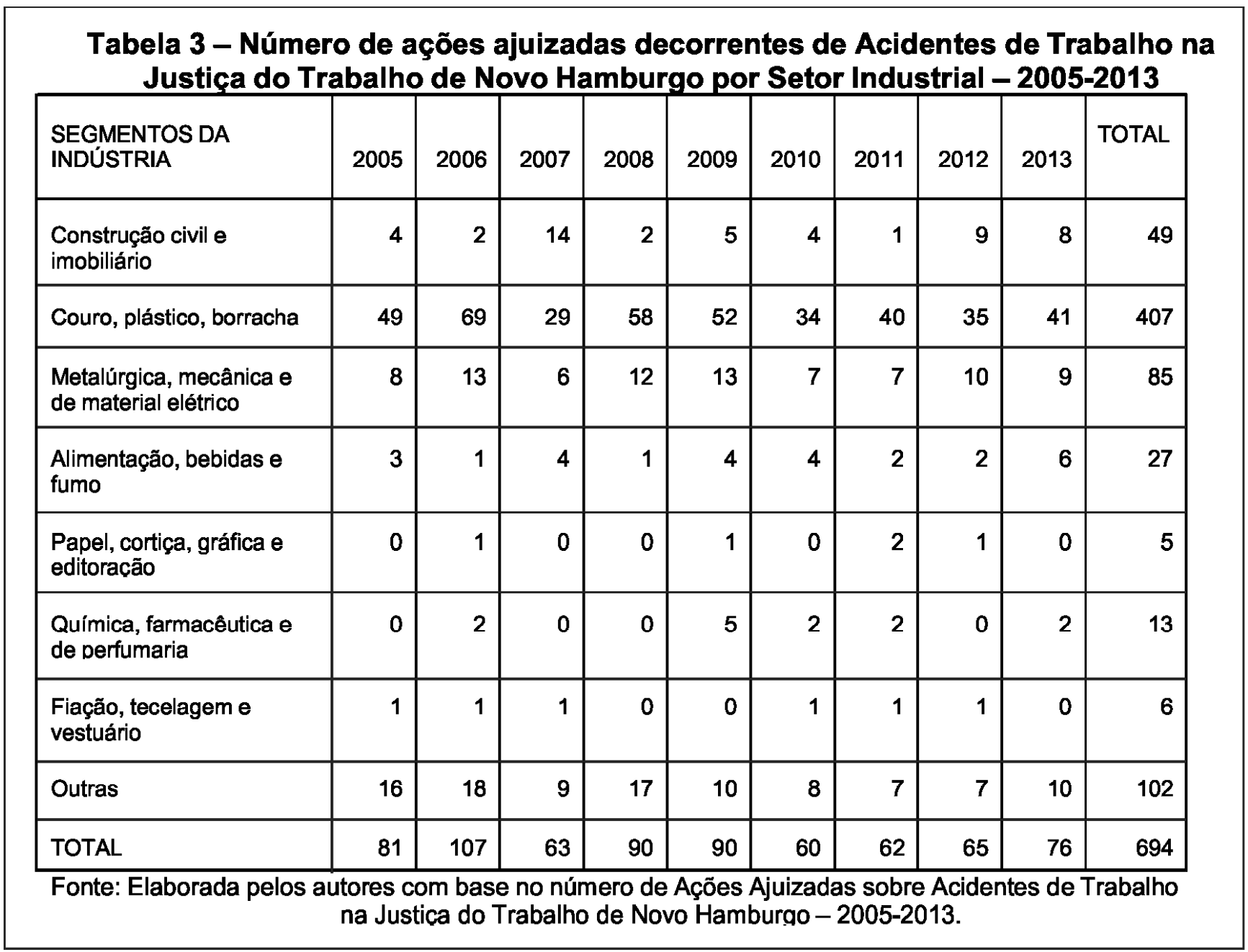

Passando para a análise das doenças relacionadas com a perda auditiva e as doenças pulmonares, considerou-se que as mesmas estariam relacionadas diretamente com o meio ambiente do trabalho e sua qualidade, inseridas, portanto, 37 BRASIL. Ministério do Trabalho e Previdência Social. Informações para o Sistema Público de Emprego e Renda, 2013.

38 ASSOCIAÇÃO COMERCIAL, INDUSTRIAL E DE SERVIÇOS DE NOVO HAMBURGO, CAMPO BOM E ESTÂNCIA VELHA - ACI - NH. Dados econômicos. 2013. 
dentro do que a Constituição Federal preconiza como meio ambiente. A Tabela 4 relaciona o número de ações ajuizadas de acidente de trabalho no Município de Novo Hamburgo classificadas como doenças ocupacionais no Setor Industrial no período de 2005/2013, que tiveram sentença em sede de Primeiro Grau.

A partir dos processos analisados, a pesquisa observou os processos que tinham como causa de pedir indenização em decorrência de perda auditiva e doença pulmonar. Foram identificados 31 (trinta e um) processos nas cinco Varas do Trabalho de Novo Hamburgo, assim discriminados por ano de distribuição:

Tabela 4 - Número de processos identificados com causa de pedir indenização em decorrência de perda auditiva e doença pulmonar nas cinco varas do trabalho de Novo Hamburgo discriminados por ano de distribuição - 2005-2013

Quanto à perda auditiva, constatou-se que foram encontrados 26 processos que objetivavam indenização, sendo que o maior número de ações neste sentido foi ajuizado no ano de 2006 e 2008, havendo uma redução a partir daquele ano. O percentual de ajuizamento em 2013 equiparou-se ao ano de 2005, início efetivo da competência da Justiça do Trabalho para conhecimento da matéria.

A Tabela 5 - apresenta a propositura de ações pelo setor industrial em decorrência de perda auditiva e doença pulmonar.

Tabela 5 Número de processos identificados com causa de pedir indenização em decorrência de perda auditiva e doença pulmonar nas cinco varas do trabalho de Novo Hamburgo discriminados por setor industrial - 2005-2013

A identificação das doenças (perda auditiva e pulmonar) por meio dos julgados também permitiu verificar que o setor metalúrgico recebeu o maior número de ações (9), seguido pelo setor calçadista (9), setores de indústria plástica (5), do couro (4) e setor da indústria da borracha (4).

Relacionando os dados obtidos junto à Previdência Social, constantes na Tabela1, é possível perceber que o número de ações ajuizadas postulando benefícios face ao acidente de trabalho (Tabela 2) é reduzido. Ou seja, embora o número de acidentes possa ser considerado alto (9.681 acidentes de trabalho), o número de ações ajuizadas no período de 2005-2013 (968 ações) corresponde tão somente a 10\% (968). Uma hipótese justificadora das diferenças encontradas poderá ser o período 


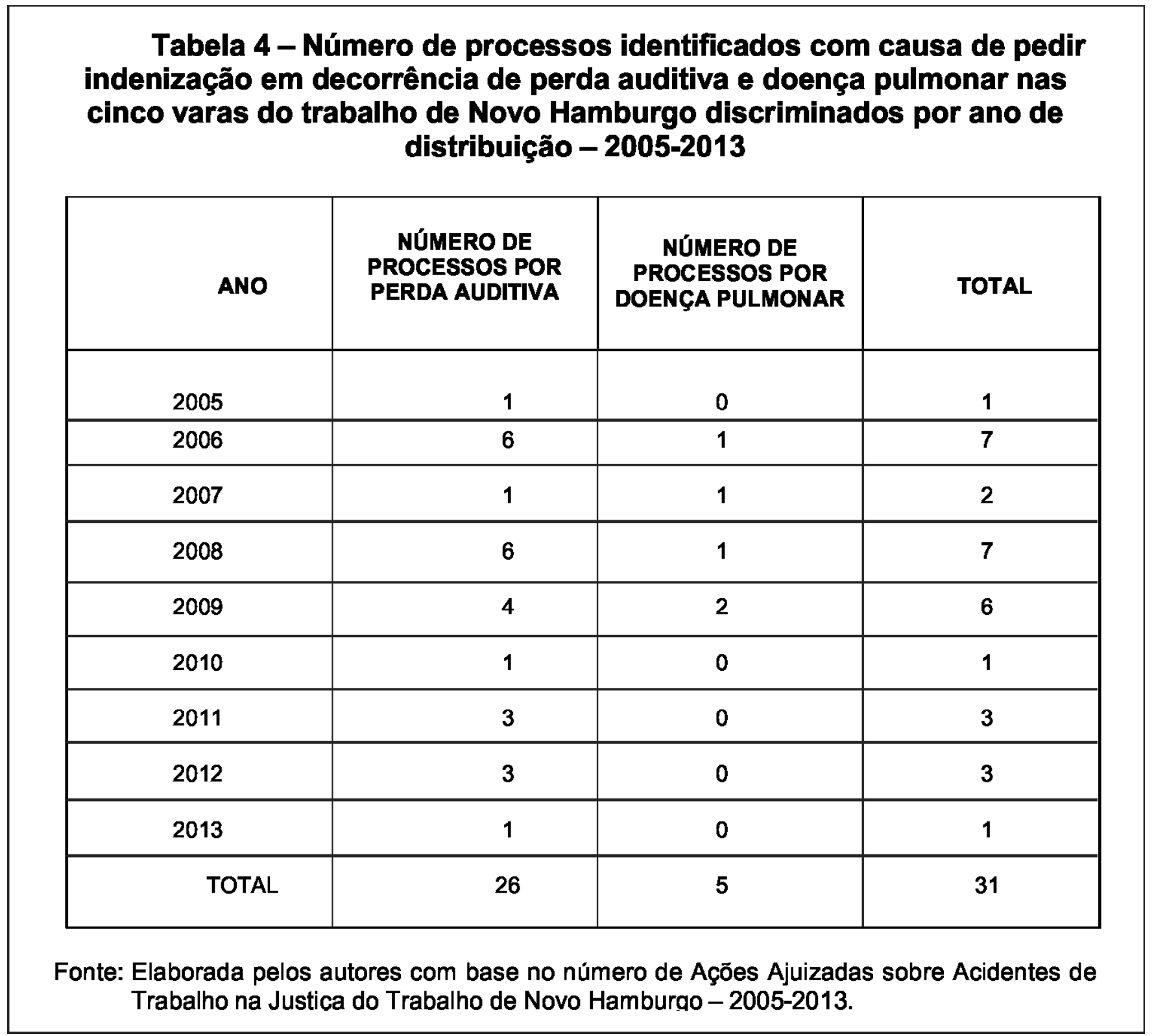

em que o trabalhador se encontra em benefício previdenciário, pois poderá ocorrer o ajuizamento após o retorno ao trabalho, ultrapassado o período de estabilidade. A análise dos dados das Tabelas 1 e 2 permitem dizer que a pequena demanda no Poder Judiciário pode estar aliada também a alguns fatores, como:

O empregado acidentado está trabalhando, gozando da garantia provisória de empregado (desde a alta do benefício até um ano após);

O empregado acidentado está trabalhando, foi reabilitado ou não teve sequelas e permanece no emprego onde ocorreu o infortúnio;

A possibilidade de ser despedido caso resolva promover ação contra o empregador; O desconhecimento do direito a uma indenização/reparação; 


\begin{tabular}{|c|c|c|c|}
\hline \multicolumn{4}{|c|}{$\begin{array}{c}\text { Tabela } 5 \text { - Número de processos identificados com causa de pedir } \\
\text { indenização em decorrência de perda auditiva e doença pulmonar nas cinco } \\
\text { varas do trabalho de Novo Hamburgo discriminados por setor industrial } \\
2005-2013\end{array}$} \\
\hline SETOR & AUDITIVA & PULMONAR & \\
\hline CALÇADO & 9 & 0 & \\
\hline METALÚRGICA & 7 & 2 & \\
\hline PLÁSTICO & 4 & 1 & \\
\hline BORRACHA & 3 & 1 & \\
\hline COURO & 3 & 1 & \\
\hline TOTAL & 26 & 5 & \\
\hline
\end{tabular}

O empregado já está em novo emprego e teme perdê-lo, pelo simples ajuizamento de demanda trabalhista, ou pela necessidade de ausentar-se por ocasião das audiências; O desinteresse em litigar face à morosidade do Poder Judiciário;

O não reconhecimento pelo INSS da relação de causalidade entre o acidente/ doença e trabalho, o que implica a necessidade de ajuizamento de ações junto à Justiça Estadual para a configuração do nexo epidemiológico.

Já o alto percentual de acidentes de trabalho do setor industrial $(71,69 \%)$ indicado na Tabela 2 está relacionado à vocação inicial e conjuntural do município de Novo Hamburgo, ainda um polo industrial, atualmente mais diversificado em relação à produção coureiro-calçadista.

Em relação às doenças ocupacionais, mais especificamente perda auditiva e doença pulmonar, dos 31 (trinta e um) processos que foram analisados sob a forma de julgamento, inicialmente pela Justiça do Trabalho de Novo Hamburgo e, posteriormente, pelo Tribunal Regional do Trabalho da Quarta Região, que abrange o Estado do Rio Grande do Sul, constatou-se, então, que em Julgamento de Primeira Instância, em 21(vinte e um) processos não restou demonstrado o nexo de causalidade entre a doença e o trabalho, razão pela qual foram julgados 
improcedentes; em 9 (nove) processos, houve o reconhecimento de que a doença apresentada pelo empregado e o trabalho tinham relação de causalidade, pois foram adquiridas ou majoradas pelo ambiente de trabalho (sentenças procedentes e parcialmente procedentes). E em uma houve o término sem análise do mérito.

O pequeno número de processos relativos ao acidente de trabalho, especialmente a doença ocupacional na proporção ao número em si de acidentes, demonstra que o sistema ainda é falho e é possível afirmar que há uma ausência de comunicação: o trabalhador não faz a busca de seu direito por que a Justiça não comunica adequadamente; o juiz julga o caso específico porque não conhece os demais; o advogado não conhece a realidade do trabalhador e não faz a comunicação correta dos fatos. O sistema social e o sistema jurídico apresentam, portanto, interferências que resultam em decisões que nem sempre refletem a realizada dos fatos. Todos são partícipes do mesmo sistema, operando em rede que ainda se apresenta com perturbações.

$\mathrm{Na}$ análise qualitativa dos julgamentos realizados pelas Varas do Trabalho de Novo Hamburgo e das decisões reformadas ou não pelo Tribunal Regional do Trabalho da Quarta Região, constatou-se a dificuldade do julgador em expressarse de forma clara sobre o meio ambiente do trabalho. As decisões de maneira significativa vinculam a existência de doença ocupacional à atividade desenvolvida, referem que faltou (ou não) a prevenção quanto à segurança do trabalhador. Foi possível verificar, entretanto, que a despeito de laudos que não reconhecem o nexo causal entre a doença ocupacional e o trabalho, o julgador está atento à proteção do trabalhador, embora nenhuma decisão (das 31 analisadas) tenha mencionado o princípio da proteção ao trabalhador.

Nas sentenças trabalhistas relacionadas ao tema (perda auditiva e doença pulmonar), os magistrados não empregaram em seus argumentos de forma expressa os princípios da prevenção e da precaução do Direito Ambiental, mesmo estes acurando questões basilares de proteção do meio ambiente laboral. Ora, as decisões dos magistrados encontram-se no âmbito da Justiça do Trabalho e permeiam em geral as relações empregatícias, mas a proteção do trabalhador é parte fundamental do direito do obreiro. Embora haja o reconhecimento da necessidade de prevenção pelo empregador, a Justiça do Trabalho ainda não se 
apropriou integralmente do meio ambiente laboral, na medida em que diversas decisões baseiam-se apenas no laudo pericial, não havendo referência de maneira expressa aos princípios da prevenção e da precaução.

Da apreciação dos julgados analisados, verificou-se que, em muitos casos, embora o empregado estivesse exposto aos agentes insalutíferos causadores de moléstias ocupacionais no ambiente laboral, o julgador, ao decidir, avalia maiormente o resultado do laudo pericial e o histórico ocupacional do trabalhador. Tal fator muitas vezes resulta em menores modificações no que se refere à mitigação dos agentes prejudiciais no ambiente laboral.

A análise realizada também mostra que a expressão "meio ambiente do trabalho" não está referida de forma clara tanto nas petições dos advogados envolvidos quanto nas decisões dos magistrados analisadas. A parte que envolve a segurança e a saúde do trabalhador é de suma importância e assim deve ser considerada nos embates jurídicos.

Neste sentido, importante trazer as reflexões de Streck que é um dos principais críticos do poder discricionário do intérprete e da baixa constitucionalidade das decisões judiciais. No tema em questão, há a necessidade de uma resposta adequada "à Constituição e não à consciência do intérprete". Sua defesa está em assegurar a força normativa da Constituição e que o texto constitucional deve ser "levado a sério", ou seja, o compromisso com a "Constituição e com a legislação democraticamente construída, no interior da qual há uma discussão, no plano da esfera pública, das questões ético-morais da sociedade". ${ }^{39}$

Por tudo isto, compartilha-se com a denúncia de Streck de que "milhares de processos são 'resolvidos' no atacado..!. Não mais discutimos causas, pois passamos a discutir teses jurídicas...! [...] E as ações são julgadas por 'pilhas'" ${ }^{40}$ Por isso, a importância da presente pesquisa em examinar como os magistrados vêm se posicionando sobre demandas de trabalhadores que buscam indenização por doenças ocupacionais. Ao fazer esta opção, compartilha-se que, com o dizer de Streck, "discutir as condições de possibilidade da decisão judicial é, antes de tudo, uma questão de democracia" e para o autor não seria necessário "acentuar 39 STRECK, Lenio Luiz. $\mathbf{0}$ que é isto - decido conforme minha consciência? Porto Alegre: Livraria do Advogado, 2011, v. 1 (Coleção o que é isto?), p. 104.

40 STRECK, Lenio Luiz. O que é isto - decido conforme minha consciência? p. 87. 
que a crítica discricionariedade judicial não é uma 'proibição de interpretar'". Afinal, "interpretar é dar sentido (Simmgebung). É fundir horizontes. E o direito é composto por regras e princípios, 'comandados por uma Constituição'". ${ }^{41}$

O Direito não deve ser observado como algo compartimentado. É necessário que os operadores compreendam o caso em que atuarão, verificando as questões ambientais em tela, deixando a subjetividade do pensamento judicial. Ainda, ao surgirem decisões na Justiça do Trabalho que considerem o Direito Ambiental como parte integrante dos direitos do trabalhador, há de causar uma reação em cadeia, pois estas decisões serão utilizadas na forma de jurisprudência, para assim alterar outros casos de acidente do trabalho.

\section{CONSIDERAÇÕES FINAIS}

Embora a Constituição Federal tenha reconhecido o direito a um meio ambiente equilibrado, sem excluir da apreciação o meio ambiente do trabalho, o presente estudo demonstrou que o assunto permanece muito a margem do mínimo necessário, quanto mais do ideal. Os dados obtidos junto ao Ministério do Trabalho e Emprego, Ministério da Previdência Social e Justiça do Trabalho de Novo Hamburgo ratificam a precariedade da relação laboral, demonstrando que o empregado e o empregador precisam qualificar-se neste sentido.

Quanto aos magistrados, entretanto, ainda se torna necessário um maior conhecimento dos conceitos e da realidade do ambiente laboral. A análise comprovou a hipótese de pesquisa, qual seja: a Justiça do Trabalho de Novo Hamburgo ao condenar empresas por doença ocupacional, mais especificamente por perda auditiva e patologia pulmonar, não se utiliza de fundamentação que realmente seja vinculada a uma análise ampla do meio ambiente do trabalho, mas sim apenas baseia suas decisões em aspectos pontuais e individualizados apresentados nas demandas individuais e com base em laudos periciais e prova testemunhal.

A pesquisa possibilitou, assim, verificar o quão complexo é o sistema social, econômico e judicial no que tange ao meio ambiente do trabalho. Cada parte trabalhador - empresa - observa a si individualmente, com pouca interação do $\overline{41}$ STRECK, Lenio Luiz. O que é isto - decido conforme minha consciência? p. 106. 
outro. O Poder Judiciário, por sua vez, também analisa, individualmente, sem a percepção do todo.

É um círculo vicioso: o advogado não postula e o magistrado nada fala sobre o meio ambiente do trabalho, ou seja, o sistema interno da justiça do trabalho reproduz uma visão restrita do ambiente laboral. Essa crítica também deve ser levada ao ensino jurídico que está aprisionado no paradigma positivista que sustenta as contradições do sistema jurídico ao considerar o direito como uma mera racionalidade instrumental. Em pleno paradigma do Estado Democrático de Direito e de uma Constituição Socioambiental de Direito pouco se fala em direito ambiental do trabalho e da necessária interdisciplinaridade para compreender o ambiente laboral no seu todo.

Conclui-se, portanto, a necessidade premente de apropriação dos conceitos e do reconhecimento da importância do meio ambiente laboral. A atualização sob o viés interdisciplinar de todos os atores envolvidos, especialmente dos magistrados e advogados, é urgente. As postulações devem ir além de meros pedidos repetitivos e sem qualquer embasamento. As decisões devem ter uma fundamentação concreta, baseado não apenas na legislação trabalhista, mas também observando a realidade laboral do trabalhador. A decisão deve ainda ter um caráter punitivo e educativo a ambos, empregado e empregador.

\section{REFERÊNCIAS DAS FONTES CITADAS}

AMERICAN SPEECH-LANGUAGE-HEARING ASSOCIATION (ASHA). Conductive hearing loss. Rockville, MD 20850, USA, 2014. Disponível em: <http://www.asha.org/public/hearing/ Conductive-Hearing-Loss>. Acesso em: 09 jun. 2016.

AQUINO, Sérgio Ricardo Fernandes de. Instrução sustentável da UNASUL por meio da entropia e hermenêutica heterorreflexiva. Revista Eletrônica Direito e Política, Programa de PósGraduação Stricto Sensu em Ciência Jurídica da UNIVALI, Itajaí, v.8, n.3, $3^{\circ}$ quadrimestre de 2013, p. 1703-1728. Disponível em: <www.univali.br/direitoepolitica>. Acesso em: 30 jun. 2017.

AQUINO, Sérgio Ricardo Fernandes de. Bauman e a crítica sobre a perda da dignidade da pessoa humana em tempos líquidos. Revista Húmus. v. 6, n. 18, p.70-88, 2016, p. 70-88. Disponível em: <http://www.periodicoseletronicos. 
ufma.br/index.php/revistahumus/article/view/6327/3847>. Acesso em: 03 jul. 2017.

ASSOCIAÇÃO COMERCIAL, INDUSTRIAL E DE SERVIÇOS DE NOVO HAMBURGO, CAMPO BOM E ESTÂNCIA VELHA - ACI - NH. Dados econômicos. Disponível em: < http://www.acinh.com. br/servicos/dados-da-regiao/novo-hamburgo>. Acesso em: 11 jul. 2016.

BAKER-SHELLEY, Alex; ZEIL-ROZEMA, Annemarie Van; MARTENS, Pim. A conceptual synthesis of organisational transformation: How to diagnose, and navigate, pathways for sustainability at universities? Journal of Cleaner Production. v. 145, p. 262-276, March 2017. Disponível em: < http:// www.sciencedirect.com/science/article/pii/S0959652617300331>. Acesso em: 03 jul. 2017.

BARDIN, Laurence. Análise de Conteúdo. Tradução de Luís Antero Reto e Augusto Pinheiro. São Paulo: Edições 70, 2011.

$\mathrm{BECK}$, Ulrich. La Sociedad del riesgo mundial: em busca de la seguridade perdida. Traducción de Rosa S. Carbó. Barcelona: Paidós Ibérica, 2008.

BOSSELMANN, Klaus. Direitos Humanos, Meio Ambiente e Sustentabilidade. In: SARLET, Ingo Wolfgang. Estado Socioambiental e Direitos Fundamentais. Porto Alegre: Livraria do Advogado, 2010.

BRASIL. Ministério da Saúde. Cadernos de Atenção Básica, n. 5. Brasília: Ministério da Saúde, 2002. Disponível em:<http://bvsms.saude.gov.br/bvs/publicacoes/cd03_12.pdf>. Acesso em: 06 jan. 2017.

Ministério da Saúde. Secretaria de Atenção à Saúde. Pneumoconioses. Brasília: Editora do Ministério da Saúde, 2006. Disponível em: <http://bvsms.saude.gov.br/bvs/publicacoes/ protocolo_pneumoconioses.pdf>. Acesso em: 06 jan. 2017.

Ministério do Trabalho e Previdência Social. Informações para o Sistema Público de Emprego e Renda, 2013. Disponível em: <http://bi.mte.gov.br/bgcaged/caged_perfil_municipio/index. php>. Acesso em: 06 jan. 2017.

CAPRA, Fritjof. O Ponto de Mutação: A Ciência, a Sociedade e a Cultura Emergente. Traduzido por Álvaro Cabral. São Paulo: Cultrix, 2006

CAPRA, Fritjof. Falando a Linguagem da Natureza: Princípios da Sustentabilidade. In: STONE, Michael K.; BARLOW, Zenobia. Alfabetização Ecológica: a educação das crianças para um mundo sustentável. Traduzido por Carmem Fischer. São Paulo: Cultrix, 2016.

CARVALHO, Sonia Aparecida de; AQUINO, Sérgio Ricardo Fernandes de. O Modelo de 
Decrescimento, Crescimento e Desenvolvimento Sustentável Diante do Paradigma de Sustentabilidade. Rev. FSA, Teresina, v. 14, n. 1, art. 4, p. 79-105, jan./fev. 2017. Doi: http:// dx.doi.org/10.12819/2017.14.1.4.

DERANI, Cristiane. Direito ambiental econômico. 3. ed. São Paulo: Saraiva, 2008.

FENSTERSEIFER, Tiago. Direitos Fundamentais e proteção do ambiente: a dimensão ecológica da dignidade humana no marco jurídico-constitucional do Estado Socioambiental de Direito. Porto Alegre: Livraria do Advogado, 2008.

GARCIA, Gustavo Filipe Barbosa. Meio Ambiente do Trabalho no Contexto dos Direitos Humanos Fundamentais e Responsabilidade Civil do Empregado. Doutrinas Essenciais de Direito do Trabalho e da Seguridade Social, v. 3, p. 543-562, set./ 2012.

GUATTARI, Félix. As Três ecologias. 10. ed. Campinas, SP: Papirus, 2000.

KATES, Robert W. Readings in Sustainability Science and Technology. CID Working Paper n. 213. Center for International Development, Harvard University. Cambridge, MA: Harvard University, December, 2010, p. 16-19.

LEITE, José Rubens Morato; AYALA, Patryck de Araújo. Dano Ambiental: do individual ao coletivo extrapatrimonial. 7. ed. rev. atual. e ampl. São Paulo: Revista dos Tribunais, 2015.

MACIEL, Fernando. Ações Regressivas Acidentárias. 2. ed. São Paulo: LTR, 2013.

MELLO, Simão Raimundo. Direito Ambiental do trabalho e a saúde do trabalhador. São Paulo, LTr, 2013.

PENA-VEJA, Alfredo. O despertar ecológico: Edgar Morin e a ecologia complexa. Traduzido por Renato Carvalheira do Nascimento e Elimar Pinheiro do Nascimento. Rio de Janeiro: Garamond, 2010.

PIANTÁ, José Antonio de Barros. Perícias do trabalho. Porto Alegre: Next, 2011.

PORTO-GONÇALVES, Carlos Walter. A globalização da natureza e a natureza da globalização. 2. ed. Rio de Janeiro: Civilização Brasileira, 2006.

SACHS, Ignacy. Desenvolvimento includente, sustentável, sustentado. Rio de Janeiro: Garamond, 2004.

SACHS, Jeffrey. An economist's view of health Bulletin of the World Health Organization. 
Genebra, v. 80, n.2, p.167-169, jan. 2002. Disponível em: <http://www.scielosp.org/scielo. php?script=sci_arttext\&pid=S0042-96862002000200014 >. Acesso em: 30 jun. 2017.

SARLET, Ingo Wolfgang. Estado Socioambiental e mínimo existencial (ecológico?): algumas aproximações. In: SARLET, Ingo Wolfgang. Estado Socioambiental e Direitos Fundamentais. Porto Alegre: Livraria do Advogado, 2010.

STERN, Nicholas. O Caminho para um mundo mais sustentável. Traduzido por Ana Beatriz Rodrigues. Rio de Janeiro: Elsevier, 2010.

STRECK, Lenio Luiz. $\mathbf{O}$ que é isto - decido conforme minha consciência? Porto Alegre: Livraria do Advogado, 2011, v. 1 (Coleção o que é isto?).

Recebido em: março/2017

Aprovado em: junho/2017 